\title{
Dansa dyonisiaca: futebol brasileiro, Dionísio nietzschiano
}

\author{
Helcio Herbert Neto*
}

Resumo: A figura de Dionísio assume diversas feições ao longo da obra de Friedrich Nietzsche (1844-1900). A questão do dionisíaco, tão instável nos trabalhos do autor alemão, vai suscitar o interesse de intérpretes brasileiros quando o futebol estiver sob observação. O propósito deste artigo é discutir apropriações feitas nesse sentido a partir dos conceitos do filósofo desde a primeira metade do século XX. Comentadores e o próprio autor reconhecem que há inflexões a respeito desse tema na obra nietzschiana. $\mathrm{O}$ debate adquire outro grau de complexidade no momento que é levada em consideração a ampla circulação dos elementos futebolísticos no Brasil, sua estreita ligação com a identidade nacional e com a cultural popular no país.

Palavras-chave: Nietzsche, Futebol brasileiro, Dionísio, nacionalismo, política, estética.

* Universidade Federal do Rio de Janeiro, Rio de Janeiro, Rio de Janeiro, Brasil.

ORCID https://orcid.org/0000-0002-4168-0749

Correio eletrônico: helcio.neto00@gmail.com 
Herbert Neto, $\mathrm{H}$.

“A palavra 'Dioniso' significa tudo isso: não conheço simbolismo mais elevado que esse simbolismo grego, o das dionisíacas (Nietzsche, Crepúsculo dos Idolos $^{1}$ )

Dionísio e o termo derivado dessa figura, o dionisíaco, atravessam a obra do filósofo alemão Friedrich Nietzsche (18441900). O aparato conceitual nietzschiano erguido em torno desse símbolo mitológico é múltiplo e denso, conforme o próprio autor reconhece no fragmento acima, que consta em Crepúsculo dos Ídolos - Ou como filosofar com o martelo, de 1888. Elaborado a partir da Antiguidade Grega, o conceito extrapola esse recorte temporal e serve ao autor para tratar até da modernidade. A maneira como essa discussão aparece na filosofia nietzschiana varia e comentadores identificam mudanças relevantes entre as publicações de juventude e as da fase madura. No Brasil, perspectivas a respeito da cultura popular e, especificamente, do futebol se apropriaram dessa noção para propor reflexões sobre particularidades do país.

Se, em trabalhos anteriores, já houve o esforço para identificar a que Dionísio se refere Nietzsche nas diferentes passagens de sua obra, o propósito aqui é compreender o que a expressão dionisíaco significa em suas ocorrências nos textos a respeito das peculiaridades brasileiras, com ênfase para as expressões futebolísticas. Embora mais filósofos que compõem a tradição do pensamento ocidental tenham se debruçado sobre a tragédia, de Aristóteles a outros autores alemães do século XIX, há indicativos de que a principal influência para os usos do conceito no Brasil foi nietzschiana. A proposta assume, assim, tantos desafios quanto os presentes na delimitação conceitual desse problema ao longo do pensamento de Nietzsche.

Um indício importante para essa discussão é a questão nacional. O sentimento germânico atravessa as asserções de Nietzsche a respeito da verve de Richard Wagner e da arte trágica entre os alemães

1 Todas as citações das traduções de Nietzsche são dos livros publicados pela Cia. das Letras, conforme indicados nas referências.

70 | Cad. Nietzsche, Guarulhos/Porto Seguro, v.42, n.3, p. 69-88, setembro/dezembro, 2021. 
que lhe eram contemporâneos. Embora isso perca força nos livros da maturidade do autor, é permitido estabelecer uma relação com as apropriações locais do dionisíaco. $\mathrm{O}$ conceito foi entendido por muitos como um traço distintivo da brasilidade no futebol. Seus múltiplos sentidos também precisam ser levados em consideração. As traduções para a língua portuguesa já demonstram as ambivalências em torno dessa figura mitológica: há diferentes grafias, como as já mencionadas Dioniso e Dionísio. A opção aqui será pela última. A partir dessa breve apresentação, este artigo terá três itens.

O intuito do primeiro é discutir os critérios adotados pelos comentadores para a segmentação da obra de Nietzsche em diferentes fases. Entre os autores selecionados, há um entendimento sobre a necessidade de não enxergar o pensamento nietzschiano como algo inteiriço ou unívoco. A intenção do segundo é encarar a maneira pela qual as perspectivas acerca de Dionísio surgem, primeiramente, em debates de grupos de intelectuais em um período de intensas reflexões sobre a identidade no Brasil e, em seguida, na produção acadêmica. Para acompanhar esses desdobramentos, serão observadas publicações desde a primeira metade do século XX. No terceiro, por fim, serão expostas as considerações finais.

\section{Quem são os Dionísios de Nietzsche?}

Para compreender as nuances que envolvem o conceito, é preciso propor uma abordagem que confira movimento diante dos diferentes regimes de historicidade presentes nas leituras a partir da obra de Nietzsche. A despeito de se ater a apropriações dessa noção em círculos intelectuais e acadêmicos, este trabalho tem como objetivo observar os seus usos diante do futebol - prática esportiva, de lazer e cultural que atravessa os costumes das camadas sociais brasileiras desde o último século do segundo milênio. Ante alterações tão intensas quanto variadas, não é possível a mera aplicação de um método estanque ou o simples enquadramento dessas dinâmicas: é 
Herbert Neto, H.

necessário buscar uma aproximação que acompanhe os ritmos da cultura popular (Neto, 2019). Essa conduta se deve ao fato de que os elementos do universo futebolístico fundamentaram interpretações a respeito, inclusive, do que é ser brasileiro.

Trata-se, então, de reconsiderar de que forma essa discussão foi retomada em um recorte temporal tão diferente. Além disso, os aspectos conjunturais àquela altura no Brasil diferem muito dos que podem ser vistos no contexto de Nietzsche. Mesmo assim, a pluralidade dessa figura mitológica chama atenção no conjunto da filosofia do autor alemão. São muitos os indícios nesse sentido. A polivalência do dionisíaco pode ser ilustrada, a título de exemplo, por meio da comparação de duas publicações em especial. A primeira, que simboliza os textos de juventude, é $O$ nascimento da tragédiaOu helenismo e pessimismo, de 1872; a segunda é Ecce homo-como alguém se torna o que é, de 1908, e representa a fase madura.

Logo de partida, em $O$ nascimento da tragédia, o autor já reconhece que a concepção de arte trágica da Grécia Antiga advém da influência de Apolo e Dionísio. Ocorre, desde o princípio do livro, a proposta de que esses dois paradigmas são determinantes para a estética moderna: "O contínuo desenvolvimento da arte está ligado à duplicidade do apolíneo e do dionisíaco, da mesma maneira como a procriação depende da dualidade dos sexos, em que a luta é incessante e onde intervêm periódicas reconciliações" (GT/NT, 1, KSA 1.25). $\mathrm{O}$ trecho estabelece a oposição entre os dois impulsos - apolíneo e dionisíaco, respectivamente - e um horizonte de estagnação a respeito da sexualidade. Ao usar como metáfora as relações sexuais, Nietzsche determina que a estética também estaria vinculada a impulsos naturais.

A figura mitológica, em Ecce Homo, assume outras feições. Se o filósofo acena com uma proposta estética ao debater a tragédia na juventude, um olhar sobre essa publicação da maturidade possibilita uma relação quase automática entre o dionisíaco e a política. $\mathrm{Na}$ 
última seção do livro, "Por que sou um destino", o autor prenuncia um novo fazer político: "Todos se baseiam inteiramente na mentira: haverá guerras como ainda não houve sobre a Terra. Somente a partir de mim haverá grande política na Terra." (EH/EH, Por que sou um destino 1, KSA 3. 366). No fragmento derradeiro, por conseguinte no final da publicação, Nietzsche destaca quem seria alia o novo antagonista: "-Fui compreendido? - Dionísio contra o Crucificado..." (EH/EH, Por que sou um destino 1, KSA 3.374). A oposição à herança cristã, com a referência ao símbolo maior do catolicismo, aqui adquire tom político.

Os dois casos demonstram os contextos distintos em que a filosofia nietzschiana evoca o conceito. São muitas as diferenças: desde as referentes aos textos - $O$ nascimento da tragédia toma forma mais dissertativa, enquanto Ecce homo é marcado pela fragmentação de aforismos -, até as referências da tradição do pensamento ocidental suscitadas para essa contraposição. $\mathrm{O}$ antagonismo da juventude tem valor natural, ao passo que na maturidade a oposição tem características políticas. É possível, contudo, identificar uma singular proximidade. Há em ambos uma disputa. Esse traço deve ser sublinhado para a discussão acerca da apreensão do Dionísio nietzschiano no Brasil. O caráter ambivalente do dionisíaco é indicado por ainda outros comentadores.

Ao se deparar com essa multiplicidade de sentidos, Lebrun (2006) se indaga justamente sobre a configuração do dionisíaco nietzschiano. Para se debruçar sobre esse questionamento, classifica de livro de iniciante $O$ nascimento da tragédia e, como tal, ambíguo (Lebrun , 2006, p. 355). Essa consideração é significativa porque é no conjunto de reflexões a respeito da arte trágica que Dionísio é inserido no pensamento de Nietzsche, embora as considerações a partir da figura mitológica sirvam de índice para a avaliação estética de tudo o que foi produzido por artistas até a Alemanha contemporânea ao escritor daquela obra. Lebrun ainda reitera a influência de Arthur 
Herbert Neto, H.

Schopenhauer na elaboração desse conceito e, por conseguinte, no próprio embate com os impulsos apolíneos narrados no livro. Todos os elementos citados são levados em conta pelo comentador para propor as diferentes fases na obra de Nietzsche. A segmentação é imprescindível para que seja enxergada a mudança da maneira como a questão do dionisíaco aparece na obra do escritor alemão.

$\mathrm{O}$ primeiro momento seria exatamente aquele marcado pelo antagonismo com Apolo que acompanha o debate sobre a arte trágica e, segundo Lebrun, "conclui-se então sobre um compromisso. Mesmo que permaneça verdadeiro não poder a música ser colocada sem aberração a serviço do drama, resta que ela ganha em investir-se na aparência, com a condição de que esta seja apresentada como suscitada por ela" (Lebrun, 2006, p. 359). O comentador também ressalta a vinculação do dionisíaco nessa fase a um todo primordial e natural: "É esse ajustamento da música ao mundo das forças que, segundo Nietzsche, explica a evolução lírica grega. A princípio, o poeta se identifica como o Uno originário" (Lebrun, 2006, p. 359). Mas, também sob o prisma de Lebrun, esses aspectos não persistem na obra de Nietzsche.

Para sustentar essa afirmação, o comentador recorre às referências utilizadas pelo filósofo alemão. Depois de identificar as citações schopenhauerianas nos escritos de juventude, Lebrun (2006) reconhece que é com Johann Goethe que o dionisíaco em Nietzsche assume outra face: "É quando Dioniso se engaja no caminho aberto de Goethe que ele se retira de sua escolta frenética para se devotar à 'auscultação' da cultura: 'dize-me que tipo de domínio exprimes'. $\mathrm{O}$ carnaval báquico chegou ao fim. O especialista, a golpes de martelo, poderá começar" (Lebrun, 2006, p. 378). Essa é a fase seguinte do conceito na obra do autor, quando a sua filosofia se lança na busca de uma nova ciência e que a proximidade com outros pensadores, a exemplo do próprio Schopenhauer e de Wagner, é deixada de lado. 
Salta aos olhos o caráter político do Dionísio do Ecce Homo, mas Lemos (2016) sublinha a necessidade de uma compreensão política também na estética nietzschiana sobre a arte trágica ainda na juventude. De acordo com o comentador, o debate travado pelo autor é atravessado por questões sociais e econômicas e não é possível negligenciar todos esses pontos na leitura de $O$ nascimento da tragédia (Lemos 2016). A filosofia apresentada nesse momento, inserida em uma conjuntura impregnada pela defesa da unificação alemã e da rivalidade com países vizinhos, requer uma aproximação que não trate o pensamento de Nietzsche de maneira teleológica ou monolítica. Diante da constatação, Lemos fornece, com uma abordagem arqueológica-genealógica, instrumentos para examinar as ranhuras no estudo da questão do dionisíaco pelo filósofo alemão.

O engajamento no projeto de cultura wagneriano é um dos principais sinais de que a discussão sobre a tragédia não se restringe à dimensão estética, mas está atrelada ao sentimento germânico. Ao descrever as dinâmicas das pulsões apolíneas e dionisíacas na Antiguidade e reconhecer que toda a potência dessa imbricação foi perdida, Nietzsche dedica as últimas seções de $O$ nascimento $d a$ tragédia ao resgate da forma superior de manifestação artística. A retomada se daria por meio da música de Wagner, gênio artístico que só poderia nascer do seio do povo alemão. $\mathrm{O}$ comprometimento com esse horizonte político tem desdobramentos decisivos para os campos da ética e da política, na aproximação com inclinações mais reativas da Alemanha naquele contexto, ligadas ao antissemitismo e à xenofobia.

Lemos (2016) sugere que a ruptura importante para observar o conjunto da filosofia nietzschiana é a inscrita nos trabalhos sobre a linguagem do autor que datam do final da mesma década. Ao tratar sobre $\mathrm{o}$ assunto, $\mathrm{o}$ filósofo abandona pressupostos que fundamentaram suas proposições até então, inclusive o da relação entre a natureza (expressa na própria concepção de Uno originário) e linguagem 
Herbert Neto, $\mathrm{H}$.

(Lemos, 2016, p. 138). A desvinculação entre essas duas ideias é o que permite, de maneira extrema, que Nietzsche rubrique a última seção de Ecce homo como Dionísio. Vale ressaltar que o próprio autor reconhece, no mesmo livro, que o distanciamento assumido perante a influência de Wagner significou uma inflexão em seu próprio pensamento (EH/EH, O caso Wagner 2, KSA 3.358).

Na maturidade, Nietzsche se empenha, em tom irônico, para ironizar tanto Wagner quanto Schopenhauer. As fissuras presentes na bibliografia legada pelo autor alemão permitem afirmar: as cores do nacionalismo, que estavam acentuadas nos livros da juventude, apareceriam com outra roupagem ao passo que o fim do século se aproximava. A relação da filosofia nietzschiana com o sentimento nacional é um aspecto raramente observado em pesquisas a respeito das apropriações realizadas por autores brasileiros. $\mathrm{O}$ recorrente uso de termos do vocabulário do autor, quando o assunto é o futebol no país, exige que mais atenção seja dedicada à associação.

\section{Futebol no Brasil: jogo dionisíaco?}

À primeira vista, o traço de disputa é o que conecta a filosofia nietzschiana e o futebol - esporte que reúne, em campo, dois times em busca de gols. Há um intervalo entre a morte do filósofo alemão e a recepção dos conceitos no Brasil, principalmente na discussão acerca da relação com o esporte. $O$ debate é retomado na década de 1930, instante em que a identidade nacional no país está em xeque. Existe uma vasta bibliografia que se debruça sobre os significados da brasilidade nesse contexto, tanto mais amplamente (Holanda, 2007; Prestes, 2014; Souza, 2017), quanto especificamente relativa ao universo futebolístico (Pereira, 1998; Negreiros, 2003; Helal, 2011; Neto, 2019). É preciso salientar que os vieses perante o tema são muitos e, em alguns casos, até opostos. Entendido como uma expressão cultural, o futebol também pode ser encarado sob o prisma 
da estética. É a essa perspectiva que Gilberto Freyre recorre para analisar a prática esportiva.

Não são poucos os autores que se empenham para avaliar a recepção de Nietzsche no Brasil por meio de Freyre (Barroso, 2013; Garcia, 2016; Dias, 2019). A chave do modernismo da primeira metade do século XX no país tem muita serventia para esses estudos. Em contrapartida, também existe uma extensa lista de iniciativas que se atém à questão do dionisíaco no futebol a partir de Freyre - e até faz menção às influências nietzschianas (Helal, 2011; Maranhão, 2006). Ainda é rara a proposta de identificar a que fase de Nietzsche o pensamento freyriano recorre ao abordar a modalidade esportiva. Lançar um olhar para os vestígios do contexto em que as suas reflexões foram publicadas, com seus aspectos sociais e políticos, colabora para essa compreensão.

Em 1938, uma delegação de brasileiros foi enviada à França para representar o país na $3^{\text {a }}$ Copa do Mundo da modalidade. O time conseguiu bons resultados no torneio e a repercussão do desempenho teve tamanho alcance que atingiu círculos intelectuais. Naquele instante, estava em vigor, desde o ano anterior, o Estado Novo. O regime autoritário, que durou até 1945, estabeleceu políticas públicas para o esporte baseadas em experiências de ditaduras europeias, com destaque para o fascismo italiano (Drumond, 2014). Às vésperas da eclosão da Segunda Guerra Militar, pensadores brasileiros refletiam a respeito dos fatores que compunham a brasilidade - e o futebol passou a ser mencionado como um desses elementos. Freyre, cuja bibliografia sobre as características étnicas e sociais ganhou relevo posteriormente, estabeleceu um marco para a estética futebolística.

Ainda com o Mundial em curso, Freyre publicou um artigo em que classificava o estilo brasileiro de conduzir a bola com os pés como dionisíaco (1938). A forma como o esporte era praticado no país manifestava a ginga e a malemolência dos habitantes do país. Há um elogio à presença de negros no time selecionado. A 
Herbert Neto, H.

afirmação sobre o jeito de jogar deve ser compreendida na totalidade do pensamento: a ode à mestiçagem perpassa a sua sociologia. $\mathrm{O}$ futebol mulato - ou "Foot-ball mulato", conforme o título conferido ao texto - seria uma particularidade brasileira. A proximidade com o conceito nietzschiano se dá por intermédio de um compatriota alemão muito influenciado pelas questões suscitadas por $O$ nascimento $d a$ tragédia, Oswald Spengler, que é inclusive mencionado em mais de uma passagem. Afetado pela vitória da equipe que representava o Brasil contra os tchecoslovacos, Freyre estabelece contra quem o estilo nacional se levantava.

São os europeus e norte-americanos que simbolizam o apolíneo. "Expressão do nosso mulatismo agil em assimilar, dominar, amollecer em dansa, em curvas ou em músicas technicas européas ou norteamericanas mais angulosas para o nosso gosto: sejam ellas de jogo ou arquitetura. Porque é um mulatismo, o nosso - psycologicamente, ser brasileiro é ser mulato" (Freyre, 1938, p. 4). O estilo europeu é tido por Freyre como método científico e como esporte socialista, em que a pessoa humana se torna mecanizada e subordinada ao todo. Da percepção do autor brasileiro a partir dos duelos entre brasileiros e estrangeiros, é possível intuir duas implicações políticas: o antissocialismo e o nacionalismo. Gomes (2008) realça o esforço do Estado Novo para conferir traços humanísticos ao regime, ao mesmo tempo em que tentava distanciar os trabalhadores das antigas associações de inclinação anarquista ou socialista com influência de imigrantes. É, no entanto, a questão racial que exige mais precaução.

Para finalizar o artigo, Freyre sintetiza seu olhar sobre a forma singular pela qual os brasileiros praticam a modalidade: "O estylo mulato, afro-brasileiro, de foot-ball é uma forma de dansa dyonisiaca" (Freyre, 1938, p.4). A simbiose entre o problema do dionisíaco e o racismo atravessa, de maneira mais nuançada, o relato de Mario Filho (2010) sobre a inserção dos negros no futebol brasileiro. Ao traçar essa trajetória, dos tempos de amadorismo com clubes aristocráticos

78 | Cad. Nietzsche, Guarulhos/Porto Seguro, v.42, n.3, p. 69-88, setembro/dezembro, 2021. 
até a popularização da modalidade e o reconhecimento dos principais jogadores negros, o escritor recorre à vocação brasileira para a prática do esporte (Mario Filho, 2010, p. 331). Vale ressaltar que é Freyre o encarregado de assinar o prefácio (2010) da edição de 1947 do livro sobre esse percurso escrito por Filho - que, aliás, é irmão do dramaturgo, cronista e jornalista Nelson Rodrigues, também autor de trabalhos sobre o futebol brasileiro (2007).

Os três publicavam textos em publicações de grande circulação, o que facilitou a aderência dessas proposições na cultura popular - a título de exemplo, é possível citar até "Foot-ball mulato", que veio a público por meio do Diário de Pernambuco. A conjuntura dessas formulações acentua a influência. As mudanças de ordem política, o princípio dos processos de industrialização e de urbanização são componentes que integram o cenário em torno da busca por traços distintivos da brasilidade nos anos 1930 no Brasil. O que foi produzido por esse círculo de intelectuais viria a ter grande ascendência sobre as novas gerações que escrevessem sobre o sentimento nacional, de maneira mais ampla, e acerca das especificidades na prática da modalidade no país.

Até mesmo em obras que não se dedicam ao futebol, mas que registram inclinações freyrianas, é permitido discernir ecos da filosofia nietzschiana. Quando Darcy Ribeiro anuncia a vocação brasileira para ser a nova Roma, lavada em sangue indígena e negro, é possível sugerir certa verve épica sobre o destino de um povo, com inspiração de Wagner (Darcy Ribeiro, 2014, p. 411). Cabe a ressalva de que, sob a ótica do sentimento germânico do século XIX, a diversidade que compõe o conjunto social do Brasil seria inadmissível. Entretanto, no momento que o foco mais recente dos autores se volta para essa modalidade esportiva, sua realidade no país e a forma dos nativos de praticá-la, as recepções e apropriações de Nietzsche mudam de figura. 
Herbert Neto, H.

Um exemplo disso é o que ocorre na segunda metade do século XX. No centro da proposta de DaMatta para a análise sobre o futebol está a ideia de dramatização. O sociólogo identifica que a prática dessa modalidade no Brasil e tudo que está em torno do esporte dramatizam candentes problemas nacionais (DaMatta, 1982). É permitido enxergar uma aproximação com a questão racial, tão enfatizada sob o signo do dionisíaco. As disputas entre os estilos brasileiro e europeu de jogar bola também aproximam as duas perspectivas. Embora busque comparações com a maneira pela qual as expressões culturais relativas aos esportes - com referência fixada, principalmente, na experiência norte-americana, conforme costumam ser as suas pesquisas -, o autor se esforça para encontrar as particularidades brasileiras na relação com o futebol. Esse é outro fator que o aproxima da leitura freyriana. Com a virada para o novo milênio, a influência dessas tendências continuaria relevante.

Helal acompanha, em várias nuances, alguns apontamentos de DaMatta e reconhece o legado desse sociólogo (2011). A discussão sobre as particularidades do estilo brasileiro desempenha função significativa. É, portanto, uma perspectiva que se prende ao nível representacional. A partir do mote do "Foot-ball mulato", é estabelecida uma comparação com a Argentina (2007). O pesquisador sublinha as formulações acerca da ideia de "fútbol criollo" - alcunha pela qual era conhecido o estilo próprio de praticar o esporte no país vizinho. $\mathrm{O}$ enquadramento nacional, novamente, remete a Freyre. $\mathrm{O}$ problema da interação entre o dionisíaco e o apolíneo reaparece na bibliografia produzida pelo mesmo escritor. $\mathrm{O}$ debate assume ainda feições ainda mais peculiares com Wisnik (2008).

O escritor emula a oposição entre Apolo e Dionísio, representados respectivamente pelos estilos europeu e brasileiro (Wisnik, 2008). Para tratar do futebol, recorre ao referencial teórico de autoria de Pasolini, para quem haveria, grosso modo, duas formas de praticar a modalidade: a primeira, chamada de prosa, é pragmática; 
a segunda, denominada poesia, tem maior rigor estético (p. 114). Os estrangeiros, especialmente os do continente em que a modalidade surgiu, simbolizariam essa forma que preza menos pela beleza. Os principais times brasileiros traduziriam esse estilo mais poético. Existe um óbvio paralelo com a leitura nietzschiana a respeito das duas pulsões que permeiam $O$ nascimento da tragédia. Ao observar as ambiguidades das dinâmicas sociais em torno da prática esportiva no Brasil, Wisnik encontra metáforas de dilemas políticos brasileiros (Wisnik, 2008, p. 114).

Júnior (2007) também menciona o embate de Apolo contra Dionísio e suas implicações estéticas. $\mathrm{O}$ seu plano não se limita ao Brasil: ao estipular reminiscências da iconografia e dos símbolos medievais no futebol contemporâneo, o historiador pretende detectar tendências gerais no comportamento dos torcedores, dos clubes e dos atletas em campo. Mas se aproxima dessa tradição ao utilizar a dança como metáfora para compreender a modalidade e ao avaliá-la por meio dos mesmos critérios que são empregados para expressões artísticas. Os conceitos de dionisíaco e apolíneo não assumem a referência do pensamento nietzschiano: é à filosofia aristotélica, particularmente às considerações a respeito da arte trágica, que Júnior se remete (Júnior, 2007) na análise da prática esportiva e de suas implicações.

Com Simas, o conceito de dionisíaco extrapola o primeiro dos limites impostos pela apreensão de Nietzsche no Brasil ainda na metade inicial do século XX. Em um trabalho que trata da cultura popular em geral, em parceria com Rufino (2018), destaca a importância desses dois impulsos para o fazer artístico: enquanto o primeiro é marcado pelo comedimento e pela disciplina, o segundo se destaca pelo extravasamento e pela embriaguez. Reforça, porém, a necessidade de buscar outras imagens para compreender as dinâmicas entre ambos. Em vez de Apolo e Dionísio, respectivamente, propõe Oxalufã e Exu (Rufino, 2018, p.118). A conjuntura local, a resistência 
Herbert Neto, $\mathrm{H}$.

com que a cultura afro-brasileira lidou com a escravidão e a maneira como os signos das religiões de matriz africana continuaram a circular em várias camadas sociais no Brasil são decisivas para essa opção.

À procura de heranças dos grandes contingentes de escravizados as referências para essa estética, ocorre no estudo uma distinção entre as diferenças entre as mitologias grega e dos orixás e o abandono da contraposição entre dionisíaco e apolíneo para que fosse empreendida uma leitura acerca da cultura popular (Simas; Rufino, 2018, p.119). A atitude simboliza o afastamento da tradição do pensamento ocidental, calcado historicamente na Antiguidade Clássica, e de suas apropriações por intelectuais no Brasil. Em outras oportunidades, Simas retoma o problema imanente ao universo futebolístico também sob esse prisma - no lugar de um estilo de jogo que se levanta contra padrões europeus, o futebol brasileiro surge como um paradigma para encontrar soluções heterodoxas, assistemáticas e iconoclastas para questões sociais (2020, p. 113). Em vez de uma visada externa, que admite o futebol como objeto de análise, o autor elabora uma abordagem diferente, que não trata a cultura africana como exótica.

\section{Dionísio contra Dionísio: por outras leituras de Nietzsche a partir do futebol}

O intuito da maior parte dos esforços dedicados ao futebol no Brasil foi delimitar como a modalidade refletia problemas nacionais, o racismo com efeito. Para isso, foram usados diferentes termos, como dramatização e representação. Dada a amplitude da prática esportiva no país e a maneira como sua popularidade se alastrou por diferentes camadas sociais, foram constantes as iniciativas que procuraram detectar dilemas da vida pública brasileira no comportamento de jogadores, torcedores e dirigentes. Do ponto de vista da cultura popular, a profunda circulação dos elementos futebolísticos possibilita também múltiplos sentidos que, em vários casos, transcendem esse esquema representacional. As leituras

82 | Cad. Nietzsche, Guarulhos/Porto Seguro, v.42, n.3, p. 69-88, setembro/dezembro, 2021. 
nietzschianas feitas por intelectuais do século XX podem oferecer alternativas para compreender essa questão.

Há uma prevalência da concepção de Dionísio da fase jovem de Nietzsche na discussão a respeito do futebol brasileiro. Com Freyre, um dos mais influentes intérpretes do Brasil do século XX, essa perspectiva ganha força. Somada ao elogio à condição mestiça da população do país, essa proposta estética serve de mote para muitos dos que se dedicam ao estudo da modalidade e das suas idiossincrasias no contexto brasileiro no terceiro milênio. Vigora, portanto, um olhar que identifica nessa expressão da cultura popular uma manifestação artística. A reiterada aproximação com a dança serve de indício disso. Diante dessa constatação, é interessante lidar com a possibilidade de que nos escritos da juventude do autor alemão há um viés político inescapável.

Assim, a paisagem se acinzenta. É possível reconhecer ecos do sentimento nacional germânico que é privilegiado em $O$ nascimento da tragédia nas apropriações brasileiras. À busca de particularidades do estilo brasileiro, Freyre descortina toda uma interpretação que se alicerça no enquadramento do Estado-nação. Essa preponderância da temática do nacionalismo reforça a prevalência do dionisíaco do jovem Nietzsche em detrimento das formulações posteriores na obra do filósofo. Reminiscências da fase inicial do pensamento nietzschiano explicariam também outros elementos das leituras a respeito da modalidade: a herança do antissocialismo, do chauvinismo e de um certo elitismo também poderiam ser atribuídos a essa influência caso seja aceita essa hipótese.

O desdobramento mais nítido disso é a negligência de outros aspectos políticos envolvidos na prática da modalidade do Brasil: o olhar dos estetas, muitas vezes, não se voltou para outras interações sociais que permeavam a realidade do país. No máximo, a oposição contra os estrangeiros é demarcada. Não é que essa inclinação freyreana não tivesse nuances políticas. Pelo contrário, a abordagem 
proposta nos anos 1930 demonstra engajamento no projeto nacional, com sua resistência a estrangeiros e a reivindicações de movimentos compostos por trabalhadores. Uma visão que realçasse a transvaloração dos valores - para usar o vocabulário do autor alemão - talvez fosse capaz de tratar de outro modo o futebol brasileiro.

O abandono das perspectivas apontadas por Ecce homo na questão da linguagem também é notável. A questão representacional, tão cara à bibliografia acerca do futebol brasileiro, não seria possível se fosse levada a cabo a subversão proposta por Nietzsche. Enquanto o descolamento do referente linguístico liberta a filosofia nietzschiana, uma atitude semelhante seria capaz de fazer com que as iniciativas que se lançam na tarefa de examinar a modalidade no Brasil superassem a sanha por identificar dramatizações ou representações sociais. A linguagem futebolística poderia ser compreendida sem a necessidade de referências, com suas transgressões e enfrentamentos. Simultaneamente, essa forma de expressão poderia ser compreendida poética e politicamente. Isso não necessariamente impediria estudos acerca das especificidades da prática esportiva e das suas condições históricas no país.

Quase um século após essas apropriações, é permitido buscar outras leituras do futebol no Brasil. Recentes debates raciais e o esgotamento das sistematizações anteriores tornam justificável o empenho nesse sentido. Mesmo que se adote como referencial a filosofia nietzschiana, novos vieses são possíveis. A contraposição entre os Dionísios da juventude e da maturidade de Nietzsche é uma saída: reforçar as rupturas no conjunto do pensamento do autor alemão, entender os diferentes acentos de sua obra e as nuances distintas de sua crítica à modernidade do filósofo. Em um contexto em que a circulação é muito ampla - como acontece na cultura popular desde o último século do milênio -, os conflitos tendem a ser ainda mais intensos. Perceber a modalidade por meio de suas disputas é uma alternativa que permite outros horizontes históricos, sociológicos e filosóficos.

84 | Cad. Nietzsche, Guarulhos/Porto Seguro, v.42, n.3, p. 69-88, setembro/dezembro, 2021. 


\section{Dionysian dance: brazilian soccer, nietzschean Dionysus}

Abstract: Dionysus has several sets throughout Friedrich Nietzsche (1844-1900) books. This question will arouse the interest of Brazilian interpreters when football is under observation. The aim of this article is to discuss the appropriations from the philosopher's concepts since the first half of the twentieth century. Commentators and the author himself saw that there are inflections about this theme in the Nietzschean work. The wide circulation of football elements in Brazil, its close connection with the national identity and with the popular cultural has to be taken into account in a consistent investigation.

Keywords: Nietzsche, Brazilian football, Dionysus, Nacionalism, Politics, Aesthetics.

\section{Referências}

BARROSO, Antonio Vinícius Lomeu Teixeira. "Um Nietzsche à brasileira: intelectuais receptores do pensamento nietzschiano no Brasil (1900-1940)". In: Revista de Teoria da História. Goiânia, jul/2013, Ano 5, Número 9, p.178-196.

DAMATTA, Roberto. "Esporte na Sociedade: Um Ensaio sobre o Futebol Brasileiro". In DAMATTA, Roberto (org.). Universo do futebol. Esporte e sociedade brasileira. Rio de Janeiro: Pinakotheke, 1982.

DIAS, Geraldo Pereira. A Recepção de Nietzsche no Brasil: Renovação e Conservadorismo. Tese (Doutorado em Filosofia). Programa de Pós-Graduação em Filosofia da Universidade Federal de São Paulo, Guarulhos, 2019.

DRUMOND, Maurício. Estado Novo e Esporte: a política e o esporte em Getúlio Vargas e Oliveira Salazar. Rio de Janeiro: 7Letras, 2014. 
Herbert Neto, $\mathrm{H}$.

FRANCO JÚNIOR, Hilário. A Dança dos Deuses - Futebol, Cultura e Sociedade. São Paulo: Companhia das Letras, 2007.

FREYRE, Gilberto. "Foot-ball Mulato". In: Diário de Pernambuco. Recife, 17 de junho de 1938, p. 4.

. Prefácio à $1^{\text {a }}$ Edição. In FILHO, Mario. O Negro no Futebol Brasileiro. MauadX: Rio de Janeiro, 2010.

GARCIA, André Luis Muniz. "Gilberto Freyre encontra Nietzsche: diálogo crítico e relevância histórica”. In: Estudos Nietzsche. Espírito Santo, jul./dez. 2016, v. 7, n. 2 , p. $8-28$.

GOMES, Angela de Castro. A Invenção do Trabalhismo. Editora FGV: Rio de Janeiro, 2008.

HELAL, Ronaldo. “'Jogo Bonito' y 'Fútbol Criollo': la relación futbolística BrasilArgentina en los medios de comunicación. In GRIMSON, Alejandro (org.). Pasiones Nacionales: política y cultura en Brasil y Argentina. Buenos Aires: Edhasa, 2007.

. "Futebol e Comunicação: a consolidação do campo acadêmico no Brasil". In: Comunicação, Mídia e Consumo. Rio de Janeiro, 2011, v. 8, n. 21, p. 11-37.

HOLANDA, Sérgio Buarque de. Raízes do Brasil. São Paulo: Companhia das Letras, 2007.

LEBRUN, Gerard. "Quem era Dioniso?". LEBRUN, Gerard. A filosofia e sua história. São Paulo: Cosac Naif, 2006, p. 355-378.

LEMOS, Fabiano. O Ofício da Origem: uma leitura de Sobre o Futuro de Nossos Estabelecimentos de Ensino de Nietzsche. Curitiba: Kotter Editorial, 2016.

MARANHÃO, Tiago. "Apolíneos e Dionisíacos" - O papel do futebol brasileiro no pensamento de Gilberto Freyre a respeito do "povo brasileiro". In: Análise Social. Lisboa, 2006, vol. XLI (179), p. 435-450.

NEGREIROS, Plínio José Labriola de Campos. "Futebol nos Anos 1930 e 1940: Construindo a Identidade Nacional”. História: Questões \& Debates. Curitiba, n. 39, p. 121-151, 2003.

86 | Cad. Nietzsche, Guarulhos/Porto Seguro, v.42, n.3, p. 69-88, setembro/dezembro, 2021. 
NIETZSCHE, Friedrich. Sämtliche Werke. Kritische Studienausgabe (KSA), 15 vols. (Organizada por Giorgio Colli e Mazzino Montinari), Berlim: Walter de Gruyter \& Co., 1988.

. Crepúsculo dos Ídolos - ou como se filosofa com o martelo. Trad. Paulo César de Souza. São Paulo: Companhia das Letras, 2010.

. Ecce Homo - Como Alguém se Torna o que é. Trad. Paulo César de Souza. São Paulo: Companhia das Letras, 1995.

. O Caso Wagner e Nietzsche contra Wagner. Trad. Paulo César de Souza. São Paulo: Companhia das Letras, 1999.

. O Nascimento da Tragédia - ou Helenismo e Pessimismo. Trad. Jacob Guinsburg. São Paulo: Companhia das letras, 1992.

PEREIRA, Leonardo Affonso de Miranda. Footballmania: Uma história social do futebol no Rio de Janeiro (1902-1938). Tese (Doutorado em História). Departamento de História do Instituto de Filosofia e Ciências Humanas da Universidade Estadual de Campinas, Campinas, 1998.

PRESTES, Anita Leocadia. Tenentismo Pós-30: Continuidade ou ruptura?. Rio de Janeiro: Consequência, 2014.

RIBEIRO, Darcy. O Povo Brasileiro - A formação e o sentido do Brasil. São Paulo: Companhia de Bolso, 2014.

RODRIGUES FILHO, Mario. O Negro no Futebol Brasileiro. Rio de Janeiro: MauadX, 2010.

RODRIGUES, Nelson. O berro impresso das manchetes: Crônicas completas da Manchete Esportiva 55-59. Rio de Janeiro: Agir, 2007, p. 24-26.

SILVA NETO, Helcio Herbert Moreira da. "Mittel, Foucault e Nietzsche - Cultura, História e Genealogia". Aproximação. Rio de Janeiro, 2020, V 15, p. 19-36.

. Programas esportivos de mesa-redonda: a questão da autoridade em pauta no gênero televisivo. Dissertação (Mestrado em Comunicação). Programa de Pós-Graduação em Comunicação da Universidade Federal Fluminense, Niterói, 2019. 
Herbert Neto, $\mathrm{H}$.

SIMAS, Luiz Antonio. "Garrinchamentos". In SIMAS, Luiz Antonio; RUFINO, Luiz; HADDOCK-LOBO, Rafael. Arruaças: Uma filosofia popular brasileira. Bazar do Tempo: Rio de Janeiro, 2020, p. 111-113.

; RUFINO, Luiz. "Acendendo velas: o exusíaco e o oxalufânico". In SIMAS, Luiz Antonio; RUFINO, Luiz. Fogo no Mato: A ciência encantada das macumbas. Rio de Janeiro: Mórula, 2018, p.113-119.

SOUZA, Jessé. Elite do Atraso - Da Escravidão à Lava Jato. Rio de Janeiro: Leya, 2017.

WISNIK, José Miguel. Veneno Remédio: Futebol e Brasil. São Paulo: Companhia das Letras, 2008.

Enviado: 01/05/2021

Aceito: 04/07/2021

88 | Cad. Nietzsche, Guarulhos/Porto Seguro, v.42, n.3, p. 69-88, setembro/dezembro, 2021. 